\title{
The schistosome enzyme that activates oxamniquine has the characteristics of a sulfotransferase
}

\author{
Livia Pica-Mattoccia, Daniele Carlini, Alessandra Guidi, Velasco Cimica, Fabio Vigorosi, \\ Donato Cioli ${ }^{+}$
}

\author{
Institute of Cell Biology, CNR, 32 via Ramarini, 00016 Monterotondo, Rome, Italy
}

Available evidence suggests that the antischistosomal drug oxamniquine is converted to a reactive ester by a schistosome enzyme that is missing in drug-resistant parasites. This study presents data supporting the idea that the active ester is a sulfate and the activating enzyme is a sulfotransferase. Evidence comes from the fact that the parasite extract loses its activating capability upon dialysis, implying the requirement of some dialyzable cofactor. The addition of the sulfate donor 3'-phosphoadenosine 5'-phosphosulfate (PAPS) restored activity of the dialyzate, a strong indication that a sulfotransferase is probably involved. Classical sulfotransferase substrates like $\beta$-estradiol and quercetin competitively inhibited the activation of oxamniquine. Furthermore, these substrates could be sulfonated in vitro using an extract of sensitive (but not resistant) schistosomes. Gel filtration analysis showed that the activating factor eluted in a fraction corresponding to a molecular mass of about $32 \mathrm{kDa}$, which is the average size of typical sulfotransferase subunits. Ion exchange and affinity chromatography confirmed the sulfotransferase nature of the enzyme. Putative sulfotransferases present in schistosome databases are being examined for their possible role as oxamniquine activators.

Key words: Schistosoma mansoni - oxamniquine - mechanism of action - sulfotransferase - drug activation

Oxamniquine (OXA) has been the cornerstone of Brazilian schistosomiasis control programs during the last 25 years and still is one of the two commercially available drugs that are effective against Schistosoma mansoni (Coura \& Amaral 2004, WHO 2002). Available information on the mechanism of action of OXA (and of the related agent hycanthone) suggests that the drug becomes active only upon transformation to an alkylating agent by an enzyme that is present in OXA-sensitive schistosomes (reviewed in Cioli et al. 1995). The evidence originates from genetic crosses between OXA-sensitive and OXAresistant $S$. mansoni showing that resistance is a recessive trait, thus implying the existence of a parasite factor that is required for drug activity (Cioli et al. 1992). In addition, a soluble extract from sensitive worms (but not from resistant worms) was capable of converting OXA into an alkylating agent that could bind covalently to the DNA and other macromolecules of the parasite (Pica-Mattoccia et al. 1989, 1992). Extracts from $S$. japonicum or $S$. haematobium (which are not sensitive to OXA), as well as extracts from mammalian tissues, failed to activate OXA. The OXA activating factor was clearly an enzyme, since it was thermolabile, protease sensitive, inactive at $0^{\circ} \mathrm{C}$ and required $\mathrm{ATP}+\mathrm{Mg}^{2+}$ in a cell-free assay (Pica-Mattoccia et al. 1992). The precise nature of the enzyme, however, was not determined, except for the broad assumption that it might be an esterifying enzyme targeting the hydroxymethyl group that is present in the drug and is

${ }^{+}$Corresponding author: dcioli@ibc.cnr.it

Received 25 May 2006

Accepted 26 June 2006 essential for its activity (Cioli et al. 1985). This study presents evidence supporting the suggestion that the OXA activating enzyme is a sulfotransferase. Activity could be partially purified, but no sufficient pure product was obtained to characterize the enzyme in molecular terms.

\section{MATERIALS AND METHODS}

Parasites - A Puerto Rican strain of S. mansoni displaying a stable sensitivity to oxamniquine (SEN) was used in most experiments (Cioli 1976). A different Puerto Rican $S$. mansoni displaying a strong resistance to OXA and hycanthone (BRR) was obtained in 1973 from Dr E Bueding (Johns Hopkins University, Baltimore, MD, US) and subsequently maintained at the Institute of Cell Biology, Rome, Italy, where it was also subjected to drug pressure and selection of survivors (Pica-Mattoccia et al. 1992). Adult schistosomes were obtained by perfusion of mice, 7 weeks or more after infection.

Enzyme assays - Worm extracts and fractions thereof were assayed for their OXA-activating capacity as described by Pica-Mattoccia et al. (1992). Briefly, male adult schistosomes were homogenized at $0^{\circ} \mathrm{C}$ in $0.1 \mathrm{M}$ Hepes $\mathrm{pH} 7.4$ containing a mix of protease inhibitors (standard buffer) and the homogenate was centrifuged at 40,000 $\times g$ to yield a soluble fraction (S-40). Rat liver extracts were prepared in the same way. Ten $\mu$ l of a mixture containing $50 \mathrm{mM}$ ATP, $50 \mathrm{mM} \mathrm{MgCl}$ and $2-8 \times 10^{5} \mathrm{cpm}^{2}{ }^{3} \mathrm{H}-\mathrm{OXA}$ were then added to $90 \mu \mathrm{l}$ of the soluble extract and incubated for $2 \mathrm{~h}$ at $37^{\circ} \mathrm{C}$. Tritiated drug was prepared by reduction of OXA aldehyde with ${ }^{3} \mathrm{H}$-sodium borohydride, following the procedure described for hycanthone (PicaMattoccia et al. 1988). The reaction was stopped by the addition of $10 \mu \mathrm{l}$ of $3 \mathrm{M} \mathrm{NaCl}$ and $250 \mu \mathrm{l}$ of chilled ethanol and kept at $-20^{\circ} \mathrm{C}$ for at least $2 \mathrm{~h}$. The reaction tubes were then centrifuged and the pellet of precipitated macromol- 
ecules was dissolved in $400 \mu 1$ PBS containing $0.25 \%$ SDS and $200 \mu \mathrm{g} / \mathrm{ml}$ proteinase K. Samples were left $30 \mathrm{~min}$ at $50^{\circ} \mathrm{C}$, extracted with two volumes of methylene chloride and the aqueous phase was counted in a liquid scintillation spectrometer. The procedure effectively eliminates free tritiated OXA (soluble in organic solvents), while allowing the estimation of macromolecule-bound radioactivity remaining in the aqueous phase (Pica-Mattoccia et al. 1992). Early experiments of this study were carried out using hycanthone, but it was later shown that OXA and hycanthone have an identical mechanism of action (Cioli et al. 1995), and most of the later experiments were carried out using OXA. When hycanthone was used, this is indicated in the text.

The quercetin sulfonation assay was carried out using $\left[{ }^{35} \mathrm{~S}\right] \mathrm{PAPS}(200 \mathrm{Ci} / \mathrm{mmole}$, New England Nuclear, Boston, MA) as co-substrate, essentially as described by Varin et al. (1987). The conversion of $\beta$-estradiol to $\beta$-estradiol sulfate was monitored using $\left[{ }^{3} \mathrm{H}\right] 17 \mathrm{~b}$-estradiol $(85 \mathrm{Ci} / \mathrm{mmol}$, New England Nuclear, Boston, MA), as described by Oeda et al. (1992).

Fractionation of extract - Five $\mathrm{ml}$ (about $50 \mathrm{mg}$ protein) of the soluble worm extract (S-40) was fractionated with ammonium sulfate and the material precipitating at $30-65 \%$ saturation (preliminarily shown to contain activity) was dissolved in $0.4 \mathrm{ml}$ standard buffer and applied to a Sephadex G-100 column $(1.6 \times 100 \mathrm{~cm})$ equilibrated with the same buffer. Elution was carried out at $4^{\circ} \mathrm{C}$ and the optical density of collected fractions $(1 \mathrm{ml})$ was read at
$280 \mathrm{~nm}$ to determine the protein profile. Ninety $\mu 1$ of each fraction was then assayed for OXA-macromolecule binding activity as detailed above. Since gel filtration removes small molecules that may be required as cofactors in the reaction, an aliquot of an extract from resistant worms was added to each assay. The column was calibrated using bovine serum albumin $(67 \mathrm{kDa})$, bovine carbonic anhydrase $(29 \mathrm{kDa})$ and cytochrome C $(13 \mathrm{kDa})$. Fractions containing the peak of activity were pooled and then applied to a DEAE-Sephadex A-50 column $(0.5 \times 2 \mathrm{~cm})$. Elution was carried out with a linear gradient $(20 \mathrm{ml})$ of $\mathrm{NaCl}$ from 0 to $0.4 \mathrm{M}$ in standard buffer and aliquots of fractions were assayed again for activity. Active fractions were dialyzed against standard buffer and applied to a 0.3 $\times 1.2 \mathrm{~cm}$ column of PAP-agarose (Sigma). Elution was carried out using $8 \mathrm{ml}$ of a linear gradient of PAPS from 0 to $0.4 \mathrm{mM}$ in standard buffer.

\section{RESULTS}

Requirements of the OXA-macromolecule binding reaction -As previously described, soluble extracts from OXA-sensitive schistosomes were able to produce the covalent binding of tritiated drug to DNA and other macromolecules (Archer et al. 1990, Pica-Mattoccia et al. 1992). The reaction required ATP and $\mathrm{Mg} 2+$ and did not occur with extracts from OXA-resistant schistosomes. Table I shows that most of the activity was lost if the extract was dialyzed against standard buffer, but the loss was not irreversible, since activity could be restored by the addition of an extract from drug-resistant worms (which is in-

TABLE I

Oxamniquine-macromolecule binding activity of different soluble extracts

\begin{tabular}{|c|c|}
\hline Components in the reaction & $\begin{array}{c}\text { Oxamniquine bound to macromolecules } \\
\left(\% \text { of complete reaction }{ }^{a}\right)\end{array}$ \\
\hline $\mathrm{SEN}^{b}$ total & 100.0 \\
\hline SEN total -ATP & 11.5 \\
\hline SEN dialyzed & 22.5 \\
\hline $\mathrm{BRR}^{c}$ total & $\leq 0.6$ \\
\hline BRR dialyzed & $\leq 0.6$ \\
\hline SEN dialyzed + BRR total & 87.5 \\
\hline SEN dialyzed + BRR dialyzed & 29.0 \\
\hline $\mathrm{SEN}$ dialyzed $+5 \mathrm{mM} \mathrm{NaSO}_{4}$ & 74.8 \\
\hline $\mathrm{SEN}$ dialyzed $+5 \mathrm{mM}\left(\mathrm{NH}_{4}\right)_{2}^{4} \mathrm{SO}_{4}$ & 80.6 \\
\hline SEN dialyzed $+5 \mathrm{mM}$ Na phosphate buffer $\mathrm{pH} 7.4$ & 21.8 \\
\hline SEN dialyzed $+5 \mathrm{mM}$ glucose- 6 -phosphate & 22.0 \\
\hline SEN dialyzed $+5 \mathrm{mM} \mathrm{Na}$ acetate & 23.2 \\
\hline SEN dialyzed $+1 \mathrm{mM}$ acetyl-CoA & 22.8 \\
\hline SEN dialyzed + 1mM NADH/NAD & 23.0 \\
\hline SEN dialyzed + 1mM NADPH/NADP & 22.6 \\
\hline SEN dialyzed $+1 \mathrm{mM}$ reduced glutathione & 21.9 \\
\hline SEN dialyzed $+1 \mathrm{mM}$ cyclic AMP & 22.9 \\
\hline SEN dialyzed $+0.1 \mathrm{mM}$ p-nitrophenyl sulfate & 20.6 \\
\hline SEN dialyzed $+0.1 \mathrm{mM}$ PAPS & 115.0 \\
\hline SEN dialyzed $+0.1 \mathrm{mM}$ PAPS - ATP & 96.2 \\
\hline SEN dialyzed + $0.1 \mathrm{mM}$ PAP & 18.3 \\
\hline SEN total $+0.1 \mathrm{mM}$ PAP & 18.6 \\
\hline BRR total $+0.1 \mathrm{mM}$ PAPS & 0.9 \\
\hline
\end{tabular}

$a$ : the complete reaction from sensitive schistosomes bound 72 pmoles oxamniquine/mg protein; $b$ : SEN, oxamniquine-sensitive schistosomes (see Materials and Methods); $c$ : BRR, oxamniquine-resistant schistosomes (see Materials and Methods) 
active in itself) to the reaction mixture. No reconstitution occurred if the extract from resistant worms was also dialyzed. This implies that a dialyzable component - in addition to MgATP - is required for the reaction to occur. Table I also shows that a number of various additions were tested and proved to be ineffective, with the exception of sulfate ions, which were able to restore most of the activity. When inorganic sulfate was replaced by the common sulfate donor in biological systems, 3'-phosphoadenosine 5'-phosphosulfate (PAPS) (Robbins \& Lipmann 1957) a complete reconstitution was produced. Reconstitution occurred even in the absence of ATP addition, indicating that ATP is needed mainly for PAPS formation (Robbins \& Lipmann 1958). In contrast, the nonsulfated PAPS analog (3'-phosphoadenosine 5'-phosphate, PAP) not only failed to restore activity, but also was able to inhibit the non-dialyzed extract. This evidence strongly suggests that the enzyme is a sulfotransferase, presumably esterifying OXA by the addition of a sulfate at the hydroxymethyl group that is present in the drug (Cioli et al. 1985). Incidentally, it is worth noting that PAPS could not be substituted by p-nitrophenyl sulfate, the sulfate donor for a special class of bacterial sulfotransferases (Kobashi et al. 1986).

OXA resistance is not due to the lack of PAPS - The notion that the sulfate donor PAPS is necessary for the activation of OXA raised the possibility that OXA resistance might be due to the lack of PAPS, or of PAPS-forming enzymes, in resistant worms. To test this hypothesis, PAPS was added to the extract of resistant worms, but this did not produce any covalent binding of tritiated drug to macromolecules (last line of Table I), thus disproving the hypothesis.

Inhibitors of the OXA activation reaction - In order to further test the hypothesis that OXA activation consists in a sulfonation reaction, a number of different compounds were tested for their ability to inhibit the drugbinding assay. The first part of Table II lists several compounds that might function as sulfotransferase substrates and might thus exert a competitive inhibition on the reaction. Of all the compounds tested, quercetin and $\beta$-estradiol - two natural substrates of sulfotransferase-mediated reactions - were clearly able to exert a strong inhibition of ${ }^{3} \mathrm{H}-\mathrm{OXA}$ binding to macromolecules. Lower levels of inhibition were also exerted by estrone and dehydroepiandrosterone, while insect steroids and some plant polyphenolic substances showed only marginal effects.

The second part of Table II lists some compounds that are known to exert various degrees of inhibition on sulfotransferases. Although fairly effective, none of them produced a complete inhibition at the concentrations tested.

Quercetin and $\beta$-estradiol are sulfonation substrates - Additional evidence for the sulfotransferase nature of the schistosome enzyme was provided by the finding that quercetin and $\beta$-estradiol not only were able to compete with OXA in the reaction, but were also able to function as sulfate acceptors under the action of schistosome ex-
TABLE II

Inhibition of oxamniquine activation by potential competitive and non-competitive inhibitors. The highest concentration tested is shown for inactive compounds

\begin{tabular}{|c|c|c|}
\hline Inhibitor & $\begin{array}{c}\text { Inhibitor } \\
\text { concentration } \\
(\mu \mathrm{M})\end{array}$ & $\begin{array}{c}\text { Inhibition } \\
(\%)\end{array}$ \\
\hline \multicolumn{3}{|l|}{ Potential substrates } \\
\hline Benzoic alcohol & 50 & 0 \\
\hline Benzyl alcohol & 200 & 0 \\
\hline Butyl alcohol & 100 & 10 \\
\hline 4-Chlorophenol & 100 & 0 \\
\hline \multirow{2}{*}{ Dehydroepiandrosterone } & 50 & 10 \\
\hline & 100 & 35 \\
\hline$\beta$-ecdysone & 250 & 10 \\
\hline Ecdysone hydroxyacetate & 250 & 12 \\
\hline 2-Deoxy-ecdysone & 250 & 0 \\
\hline 20-Hydroxy-ecdysone & 250 & 0 \\
\hline \multirow[t]{3}{*}{$\beta$-Estradiol } & 20 & 45 \\
\hline & 50 & 82 \\
\hline & 100 & 92 \\
\hline Estrone & 100 & 54 \\
\hline Hydrocortisone & 100 & 0 \\
\hline 3-Hydroxymethyl-pyridine & 100 & 0 \\
\hline Na lithocholate & 100 & 28 \\
\hline$\alpha$-Naphtol & 70 & 0 \\
\hline Polypodine B & 250 & 0 \\
\hline \multirow[t]{3}{*}{ Quercetin } & 4 & 64 \\
\hline & 40 & 85 \\
\hline & 100 & 98 \\
\hline Vanillin & 100 & 0 \\
\hline Curcumin & 100 & 18 \\
\hline Equol & 100 & 21 \\
\hline Genistein & 100 & 16 \\
\hline Rotenone & 100 & 9 \\
\hline Tyramine & 100 & 15 \\
\hline Tyrosine & 100 & 3 \\
\hline \multicolumn{3}{|l|}{ Potential inhibitors } \\
\hline 2,6-Dichloro-4-nitrophenol & 100 & 17 \\
\hline \multirow[t]{2}{*}{ Pentachlorophenol } & 50 & 10 \\
\hline & 100 & 35 \\
\hline N-Ethylmaleimide & 50 & 20 \\
\hline \multirow[t]{2}{*}{ Tetrabutylammonium chloride } & 20 & 10 \\
\hline & 100 & 38 \\
\hline
\end{tabular}

tracts. Most important, sulfate transfer to the two acceptors was mediated only by extracts of OXA-sensitive schistosomes, while the extracts of drug-resistant worms failed to produce any effect.

Table III shows that quercetin could be sulfonated by rat liver extract and that this reaction was not sensitive to competition with the oxamniquine congener, hycanthone. This indicates that the mammalian enzyme does not recognize the antischistosomal drug, as previously demonstrated (Pica-Mattoccia et al. 1992). An extract from sensitive worms was also capable to sulfonate quercetin and this reaction could be competed by free hycanthone, stressing the drug specificity of the parasite enzyme. Only marginal quercetin sulfonation was mediated by an extract from OXA-insensitive schistosomes. 
TABLE III

Sulfonation of quercetin by rat and schistosome extracts

\begin{tabular}{llcr}
\hline Source of S-40 extract & Substrate & Inhibitor & $\begin{array}{r}\text { Bound [ }{ }^{35} \text { S]PAPS] } \\
\text { (pmol/mg protein) }\end{array}$ \\
\hline Rat liver & $5 \mu \mathrm{M}$ quercetin & - & 5.1 \\
Sensitive worms & $5 \mu \mathrm{M}$ quercetin & $50 \mu \mathrm{M}$ hycanthone & 5.0 \\
Resistant worms & $5 \mu \mathrm{M}$ quercetin & - & 1.7 \\
\hline
\end{tabular}

Table IV shows that $\beta$-estradiol could be easily sulfonated by rat liver enzymes, as expected (Borthwick et al. 1993). An extract from sensitive worms was also capable to produce $\beta$-estradiol sulfonation, whereas an extract from OXA-insensitive schistosomes did not produce $\beta$-estradiol sulfate above detection level. The amount of sulfate bound to $\beta$-estradiol by schistosome extracts was much less than the amount bound under the activity of rat liver extract. This is not completely unexpected when considering that the specificity of the parasite enzyme is directed towards an unknown substrate that is likely to be - at best - only partially resembling the mammalian steroid substrate.

Fractionation and purification of the activating enzyme - An ammonium sulfate fraction of the soluble extract (S-40) of OXA-sensitive schistosomes was subjected to gel filtration analysis under non-denaturing conditions and the fractions were tested for protein content and for ${ }^{3} \mathrm{H}-\mathrm{OXA}$ binding activity. Fig. 1 shows that, while most of the protein was eluted with the column front, the bulk of enzymatic activity was eluted in a region corresponding to a molecular weight of about $30-32 \mathrm{kDa}$, in accordance with the fact that most cytosolic sulfotransferase subunits consist of around 300 amino acid residues (Petrotchenko et al. 2001).

A pool of the Sephadex fractions containing the peak of activity was applied to a DEAE-Sephadex column and eluted with a $\mathrm{NaCl}$ gradient. Fig. 2A shows that activity eluted as a single peak at about $0.2 \mathrm{M}$ salt concentration, in agreement with the behavior of other sulfotransferases.

Fractions from DEAE-Sephadex containing activity were pooled, dialyzed against standard buffer and applied to a PAP-agarose affinity column. Elution was performed with a gradient of PAPS and the results are shown in Fig. $2 \mathrm{~B}$. The single peak of activity eluting with the specific co-substrate adds further weight to the evidence that the enzyme is indeed a sulfotransferase.

\section{TABLE IV}

Sulfonation of b-estradiol by rat and schistosome extracts

\begin{tabular}{lcc}
\hline Source of S-40 extract & Substrate & $\begin{array}{c}\beta \text {-estradiol sulfate } \\
\text { (pmol/mg protein) }\end{array}$ \\
\hline Rat liver & ${ }^{3} \mathrm{H}-\beta$-estradiol & 11.6 \\
Sensitive worms & ${ }^{3} \mathrm{H}-\beta$-estradiol & 1.2 \\
Resistant worms & ${ }^{3} \mathrm{H}-\beta$-estradiol & $\leq 0.1$ \\
\hline
\end{tabular}

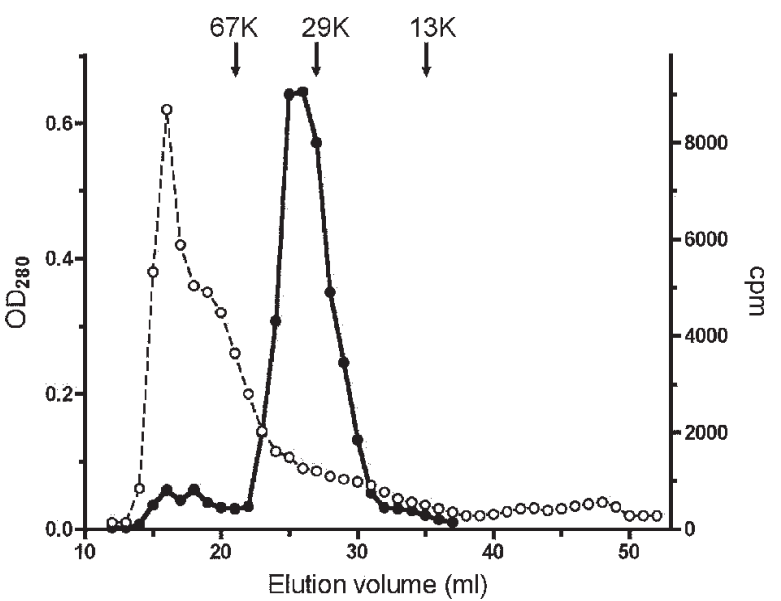

Fig. 1: gel filtration profile of an extract from oxamniquine-sensitive schistosomes. Open circles (left axis): optical density at 280 $\mathrm{nm}$; closed circles (right axis): radioactivity (cpm) of tritiated oxamniquine bound to macromolecules.

As it happens with many sulfotransferases, the OXAmacromolecule binding activity proved to be rather labile, since it was gradually lost upon simple storage at $4^{\circ} \mathrm{C}$, at the rate of about $20 \%$ /week. This makes it difficult to keep an accurate bookkeeping of activity through the various steps of the purification procedure. Nevertheless, an approximate - probably underestimated - accounting of the purification achieved is given in Table V. It should be noted that even the most purified fraction obtained from PAP-agarose still presented several bands when analyzed by SDS-PAGE (not shown).

TABLE V

Purification of the oxamniquine-binding activity

\begin{tabular}{lcc}
\hline Fraction & $\begin{array}{c}\text { Oxamniquine bound } \\
\text { to macromolecules } \\
\text { (pmol/mg protein) }\end{array}$ & $\begin{array}{r}\text { Purification } \\
\text { coefficient }\end{array}$ \\
\hline Unfractionated S-40 & 110 & 1.0 \\
30-65\% ammonium sulfate & 286 & 2.6 \\
Sephadex G-100 & 3,366 & 30.6 \\
DEAE-Sephadex A-50 & 14,179 & 128.9 \\
PAP-agarose & 39,215 & 356.5 \\
\hline
\end{tabular}



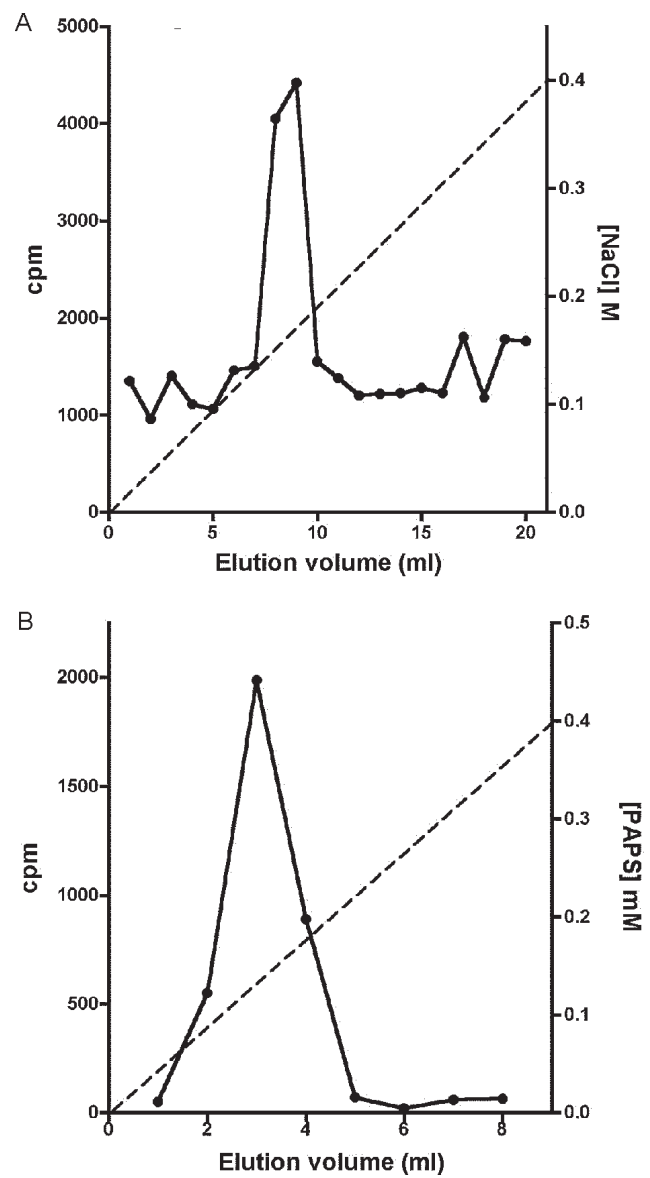

Fig. 2 A: DEAE-Sephadex elution profile of material obtained from gel filtration; B: PAP-agarose elution profile of material obtained from DEAE-Sephadex. Individual points represent radioactivity (cpm, left axis) from the oxamniquine activation assay. Dotted lines represent the concentration of the eluting substance (right axis).

\section{DISCUSSION}

This study contributes additional evidence to the available information regarding the proposed mechanism of action of OXA (Cioli et al. 1995). It was previously shown that an enzymatic activity present in OXA-sensitive schistosomes (but absent in drug resistant worms) could produce the covalent binding of OXA to the DNA and other macromolecules of the parasite (Pica-Mattoccia et al. 1992). It was postulated that the schistosome enzyme was inducing the formation of an OXA ester that would then spontaneously dissociate giving rise to an electrophilic moiety capable of alkylating parasite macromolecules (Cioli et al. 1985, 1995). The chemical nature of the postulated ester was, however, unknown and a direct identification was problematic in view of the very short half life that such an unstable compound would exhibit. Data presented here strongly support the notion that the ester is a sulfate and the OXA activating enzyme is a sulfotransferase.

The initial observation that a dialyzable cofactor is essential for the activation reaction prompted us to examine a number of potential compounds that could restore activity to the dialyzed schistosome extract. Inorganic sulfate provided a substantial re-activation and the or- ganic sulfate donor PAPS (Robbins \& Lipmann 1957) proved capable of full restoration of activity. We thus inferred that the intact parasite extract probably contains a certain amount of preformed PAPS and is very likely to contain the two key enzymes for PAPS formation from ATP and inorganic sulfate, i.e. ATP sulfurylase and adenosine 5'-phosphosulfate kinase (Robbins \& Lipmann 1958). Dialysis removes PAPS and its two building blocks (MgATP and inorganic sulfate), thus impeding the reaction to proceed. Addition of inorganic sulfate may restore activity if ATP and the two enzymes are present in adequate amounts, while addition of PAPS is obviously expected to be fully effective. A non-dialyzed extract from drug resistant worms, which is inactive per se, is capable of restoring activity because it can supply PAPS and the whole PAPS-forming machinery. PAPS donates the sulfate and is converted to PAP in the sulfotransferase mediated reaction. PAP proved unable to restore activity to the dialyzed extract and, being a reaction product, actually inhibited the activity of the intact extract.

The requirement of PAPS in the reaction of OXA activation raised the theoretical possibility that drug resistant schistosomes might fail to activate the drug because they are deficient in PAPS, but PAPS addition to the extract from resistant worms failed to confer activity, thus disproving the hypothesis.

To further validate the notion that OXA activation involves a sulfonation reaction, we asked whether known sulfotransferase substrates were able to compete with OXA in the reaction. Several compounds possessing one or more alcoholic functions - the main target of sulfonation reactions - were tested and some of them were indeed able to produce a strong competition, like the flavonoid quercetin and some mammalian steroids. The fact that only a restricted number of structures were able to compete indicates that the putative schistosome sulfotransferase, like other members of the sulfotransferase family, could have a rather stringent substrate specificity (Glatt 1997). A few of the known non-competitive inhibitors of sulfotransferases gave variable, but incomplete inhibition of the oxamniquine-macromolecule binding reaction. We interpret this as an indication that the schistosome enzyme has relatively unusual characteristics with respect to canonical sulfotransferases.

In addition, at least two of the competing compounds, i.e. quercetin and $\beta$-estradiol, were able to function as sulfate acceptor substrates under the action of a schistosome extract, when tested in classical sulfonation assays based on the use of ${ }^{35}$ PAPS and radioactive $\beta$-estradiol, respectively. The fact that extracts from OXA resistant worms were unable to produce the sulfonation of these heterologous substrates is strong evidence to support the idea that this type of drug resistance is indeed the result of a missing sulfonation activity. By the same argument, OXA activity must require a sulfonation reaction.

Ancillary evidence supporting the assumption that the OXA activating enzyme is a sulfotransferase, comes from the biochemical characteristics of the schistosomederived activity. The schistosome enzyme is found in the cytosol and elutes in gel filtration in a region corresponding to about $32 \mathrm{kDa}$ under non-denaturing conditions. Most mammalian and plant cytosolic sulfotransferases 
exhibit a native size that is twice this value and have been shown to be dimers consisting of two identical subunits. There are, however, examples of native sulfotransferases that consist of a single subunit, as is the case when a single valine to glutamic acid substitution occurs in a dimerization motif near the $\mathrm{C}$-terminus of the protein (Petrotchenko et al. 2001). The schistosome enzyme apparently belongs to this subset of monomeric proteins.

Ion exchange chromatography has often been used for the isolation of sulfotransferases (Falany et al. 1990) and the schistosome activity proved also amenable to this type of purification. The peak of activity was eluted from DEAE-Sephadex at the $\mathrm{NaCl}$ concentration of $0.2 \mathrm{M}$, but such a peak still consisted of about 20 different proteins when analyzed by SDS-PAGE. In a further purification step, the DEAE-Sephadex peak was applied to a PAPagarose affinity chromatography support and proved capable of binding and of subsequent elution with the specific sulfotransferase substrate PAPS. This constitutes additional evidence for the sulfotransferase nature of the enzyme.

Although each purification step provided some increase in the level of specific activity, no electrophoretically pure fraction could be obtained. In addition, activity proved to be quite labile and was gradually lost even upon simple storage at $4^{\circ} \mathrm{C}$, as it occurs with other sulfotransferases. Thus, we were unable to obtain sufficient amounts of high purity protein for further structural studies.

A number of heterologous anti-sulfotransferase antibodies were tested, but none of them gave consistent results when assayed in Western blots against schistosome extracts. This prevented us from attempting to clone the gene by library immunoscreening. Also, we were not successful with library screening using degenerate primers based on sulfotransferase sequences known in other species.

The recent availability of extensive $S$. mansoni EST databases and the progress in the schistosome genome sequencing (Verjovski-Almeida et al. 2003, LoVerde et al. 2004), opens the possibility of an in silico analysis of schistosome sulfotransferases, including the putative OXA-activating enzyme described in this study. Work is in progress along these lines.

\section{REFERENCES}

Archer S, El-Hamouly W, Seyed-Mozaffari A, Butler RH, PicaMattoccia L, Cioli D 1990. Mode of action of the schistosomicide hycanthone: Site of DNA alkylation. Mol Biochem Parasitol 43: 89-96.

Borthwick EB, Burchell A, Coughtrie MW 1993. Purification and immunochemical characterization of a male-specific rat liver oestrogen sulphotransferase. Biochem J 289: 719-725.

Cioli D 1976. Transfer of Schistosoma mansoni into the mesenteric veins of hamsters. Int J Parasitol 6: 349-354.

Cioli D, Pica-Mattoccia L, Archer S 1995. Antischistosomal drugs: past, present ... and future? Pharmacol Ther 68: 3585 .
Cioli D, Pica-Mattoccia L, Moroni R 1992. Schistosoma mansoni: hycanthone / oxamniquine resistance is controlled by a single autosomal recessive gene. Exp Parasitol 75: 425-432.

Cioli D, Pica-Mattoccia L, Rosenberg S, Archer S 1985. Evidence for the mode of antischistosomal action of hycanthone. Life Sci 37: 161-167.

Coura JR, Amaral RS 2004. Epidemiological and control aspects of schistosomiasis in Brazilian endemic areas. Mem Inst Oswaldo Cruz 99 (Suppl. 1): 13-19.

Falany CN, Vazquez ME, Heroux JA, Roth JA 1990. Purification and characterization of human liver phenol-sulfating phenol sulfotransferase. Arch Biochem Biophys 278: 312318.

Glatt H 1997. Bioactivation of mutagens via sulfation. FASEB $J$ 11:314-321.

Kobashi K, Fukaya Y, Kim DH, Akao T, Takebe S 1986. A novel type of aryl sulfotransferase obtained from an anaerobic bacterium of human intestine. Arch Biochem Biophys 245: 537-539.

LoVerde PT, Hirai H, Merrick JM, Lee NH, El-Sayed N 2004. Schistosoma mansoni genome project: an update. Parasitol Int 53: 183-192.

Oeda T, Lee YC, Driscoll WJ, Chen HC, Strott CA 1992. Molecular cloning and expression of a full-length complementary DNA encoding the guinea pig adrenocortical estrogen sulfotransferase. Mol Endocrinol 6: 1216-1226.

Petrotchenko EV, Pedersen LC, Borchers CH, Tomer KB, Negishi M 2001. The dimerization motif of cytosolic sulfotransferases. FEBS Lett 490: 39-43.

Pica-Mattoccia L, Archer S, Cioli D 1992. Hycanthone resistance in schistosomes correlates with the lack of an enzymatic activity which produces the covalent binding of hycanthone to parasite macromolecules. Mol Biochem Parasitol 55: 167-176.

Pica-Mattoccia L, Cioli D, Archer S 1988. Binding of tritiated hycanthone and hycanthone N-methylcarbamate to macromolecules of drug-sensitive and drug-resistant schistosomes. Mol Biochem Parasitol 31: 87-96.

Pica-Mattoccia L, Cioli D, Archer S 1989. Binding of oxamniquine to the DNA of schistosomes. Trans $R$ Soc Trop Med Hyg 83: 373-376.

Robbins PW, Lipmann F 1957. Isolation and identification of active sulfate. J Biol Chem 229: 837-851.

Robbins PW, Lipmann F 1958. Enzymatic synthesis of adenosine-5'-phosphosulfate. J Biol Chem 233: 686-690.

Varin L, Barron D, Ibrahim RK 1987. Enzymatic assay for flavonoid sulfotransferase. Anal Biochem 161: 176-180.

Verjovski-Almeida S, DeMarco R, Martins EA et al. 2003. Transcriptome analysis of the acoelomate human parasite Schistosoma mansoni. Nat Genet 35: 148-157.

WHO 2002. Prevention and control of schistosomiasis and soiltransmitted helminthiasis. Report of WHO Expert Committee, Geneva. 